\title{
Engaging students and teachers in meteorology and atmospheric sciences: the LaMMA activities
}

\author{
Valentina Grasso $^{1,2}$, Giorgio Bartolini ${ }^{1}$, Riccardo Benedetti ${ }^{1}$, Giulio Betti ${ }^{1,2}$, Valerio Capecchi ${ }^{1,2}$, \\ Bernardo Gozzini ${ }^{1}$, Ramona Magno ${ }^{1,2}$, Andrea Orlandi ${ }^{1}$, Luca Rovai ${ }^{1,2}$, Claudio Tei ${ }^{1,2}$, \\ Tommaso Torrigiani $^{1,2}$, and Federica Zabini ${ }^{1,2}$ \\ ${ }^{1}$ LaMMA Consortium, Via Madonna del Piano 10, Sesto Fiorentino (FI), Italy \\ ${ }^{2}$ Institute of Biometeorology, Italian National Research Council, Via G. Caproni 8, Florence, Italy \\ Correspondence to: Valentina Grasso (v.grasso@ibimet.cnr.it)
}

Received: 24 January 2017 - Revised: 30 March 2017 - Accepted: 4 April 2017 - Published: 4 May 2017

\begin{abstract}
Scientific institutes contribute to increase scientific awareness in local communities. They also provide students and teachers with learning opportunities outside the classroom. This is especially true when science centers create opportunities to visit laboratories or design activities based on learning by doing. LaMMA, a public consortium set up by Italian National Research Council and Tuscany Region (Italy), is the official weather service for Tuscany. In recent years LaMMA developed several educational modules on meteorology for different school grades. Activities are performed during a two-hour visit at the LaMMA laboratory. Since 2011 every year more than 1200 students come to visit LaMMA to follow one of the proposed modules on meteorology. Students are engaged in different activities and have the opportunity to visit the LaMMA weather operations room and meet the forecasters. In the last two years, an educational module on climate change based on a participatory approach was proposed to teachers of all school levels. More than 500 teachers and environmental educators from all over Tuscany participated and many of them developed a follow up project in the classroom.
\end{abstract}

\section{Introduction}

Following the modern Science-Technology-Society's (STS) approach, science education should not only transmit to students fundamental science knowledge but it should also prepare citizens to take informed decisions within society (Mansour, 2009). Research institutions can play a role in making science and society closer by also providing students with new learning opportunities outside the classroom. Many different organizations like universities, research centers, government laboratories and informal science institutions such as museums, are active in engaging the public in science. As a result, scientists are increasingly asked to participate in public outreach activities by their funding agencies and by society as a whole (Andrews et al., 2005). One of the most common outreach model is "scientist in the classroom" where experts are invited as guest speakers into the classroom. It is a way to bring the expertise of practicing professional scientists to stimulate students' learning, interest in science, and, furthermore, to invite young students to con- sider scientific careers (Laursen et al., 2007). Research institutions can be important informal settings for learning science, especially given the growing urgency of the need for scientific literacy for all (National Research Council, 2006, 2009; Shouse et al., 2007). Public outreach initiatives at research laboratories contribute to increase science awareness of local communities and also represent a great opportunity for schools' visits to increase knowledge about scientific (Mintz, 2005). Research laboratories may in fact play an important role in the overall educational system, providing students and teachers with new opportunities to achieve some of the learning objectives of a class curriculum. Visiting a science laboratory offers a "rich learning environment" that can inform classroom practice (Dusenbery et al., 2008).

Meteorology is one of the topics of the science curriculum in elementary and secondary schools. But it is also a common science topic for everyone watching weather forecasts on TV, on the Internet or just opening the weather apps on smartphones. To increase the understanding of weather phenom- 
ena, climate variability, forecast principles, and uncertainty it is important to make people aware of the scientific limits of weather predictability. There are plenty of educational and outreach activities created by weather services and research institutions to engage the public (Pandya et al., 2011, 2009), inside and outside the classroom (Finarelli, 1998). Some of these initiatives are also conceived as a way to increase community resilience to extreme weather events (Nutter et al., 2010). In this work we present the educational activities proposed by the LaMMA consortium, home of the Tuscany's weather service, to engage students and teachers and raise awareness on meteorology, weather forecasting and related atmospheric sciences.

\section{LaMMA activities}

The LaMMA Consortium (www.lamma.rete.toscana.it), is a public consortium set up by Italian National Research Council (hereafter CNR) and the Tuscany Region. It develops products and services on environmental monitoring. LaMMA is also in charge of the weather forecasting service for Tuscany. Among public outreach activities, the LaMMA Consortium provides environmental education and scientific information activities for primary and secondary schools in Tuscany, both in the form of specific projects and organized visits to laboratories. Several activities are organized to raise awareness about meteorology, climatology, biometeorology, energy saving and environmental sustainability. Activities include open days, participation at science fairs, local events organized by scientific and institutional partners, or schools' visits organized at our laboratories. LaMMA developed several educational modules on meteorology and climatology directed to different grade levels. All modules are based at the LaMMA Consortium and also include a visit to the weather operations room. Furthermore, in the last two years LaMMA took part in a training project promoted by Tuscany Region to improve teaching skills and scientific knowledge of school teachers and environmental educators. The following subsections illustrate the educational modules developed by LaMMA and proposed to students and teachers. Last section presents the results of a survey questionnaire for training evaluation.

\subsection{Meteorology modules for schools}

As part of public outreach, LaMMA developed several educational modules for schools of different grade levels. Many schools in Tuscany have been interested in visiting LaMMA laboratories to raise students' awareness on meteorology and atmospheric sciences. These modules are organized at the LaMMA centre as a two-hour lesson. Participating students have the chance to increase their knowledge about weather forecasting, meet researchers and visit the weather operations room. The main proposed modules are the following.
A basic module is proposed to elementary schools. During the first part of this lesson, a researcher gives a presentation on main meteorological concepts and illustrates key steps of weather forecasting. Later, students visit the weather operations room and see a functioning weather station. To students of elementary and middle school is also proposed the module What's up there. In this lesson basic concepts of meteorology are explained through simple experiments performed by two researchers. For the experiments selection, preferences were given to simple and illustrative activities which could be created with household objects and waste materials easy to find. During the experiments, the students are invited to make hypotheses to explain them. Afterwards, students visit the weather operations room and see a functioning weather station. A more participative module is Who wants to be a forecaster, proposed to students aged 11 and older. In the first part of the lesson, a meteorologist gives a presentation of the key steps and technologies used by forecasters. Later, students work in small groups to create their own video of a weather forecast. Part of the exercise is also the creation of an appropriate format for the forecast, whether it is a regional service or a school weather channel or whatever they choose. The edited video are then published on LaMMA website and shared on social media. Recently, a more elaborate module for high school students has been created, Atmosphere, what a Chaos. At first, a researcher gives a presentation about Chaos theory, the unpredictable nature of complex systems like the atmosphere, thus explaining the intrinsic uncertainty in weather forecasting. Afterwards, students are involved in a role-playing game, based on a cost/loss decision model, where they make decisions on the basis of a weather risk.

These activities were designed and proposed gradually. Some years ago LaMMA meteorologists were often invited as "experts" in classrooms to give talks about meteorology and weather forecasting. As the number of requests increased, a more structured educational proposal was organized at LaMMA headquarter. LaMMA visits were designed as an opportunity for schools to have an external learning experience and improve students understanding on meteorology.

The first modules to be created were "Basic weather lesson" and "Who wants to be a weather forecaster?". Next, following students' feedbacks, the module with experiments was introduced. The researchers' presentations on meteorology were sometimes evaluated as "boring" by students who were asking for more interactive lessons. The experiments module allowed for an increase in students engagement in the learning process also thanks to teaching techniques like the Inquiry Based Learning (Gibbs, 1988; Prince and Felder, 2006). The most recent module, "Atmosphere, what a chaos" was proposed to answer to the many requests of high school teachers for lessons with more references to physics and mathematics. In all modules, role playing and interactive activities were introduced to increase engagement and to emphasize the idea that science can also be fun. Fun and en- 
gagement are in fact reported in the open comments left by students within the evaluation. At the question "What did you like the most", many students attending the experiments module answered "the experiments". The video making was also reported in free comments as a very funny and appreciated activity. Furthermore, as highlighted by some quotes reported hereby, visiting LaMMA gave students the chance to better understand the science behind weather forecast. Student 1: "It was a great idea to make the experiments and let us try to answer the questions to make us think." Students 2: "For me it was a learning experience and I think that helped me to understand the great work behind the weather forecast." Student 3: "The tour was nice and helped me to realize that being a weatherman is not as easy as it may seem."

\subsection{Teachers training}

The training course for teachers is structured both into classical lectures on Climate Change and other didactic topics as well as working groups based on several participatory approaches (OST-Open Space Technology Owen, 2008; brainstorming, Osborn, 1963; World Café, Brown, 2002; role playing, Chesler and Fox, 1966, Capranico, 1997; storytelling, McDrury and Alterio, 2002, Flanagan, 2015; and concept mapping, Novak, 1990). They are aimed at the construction of competence units by teachers of different subjects. After the training, teachers are invited to create their class units in order to increase specific and cross competences of students, to enrich knowledge on Climate Change and its impacts at local level, and to develop sustainable behaviors and best practices. Since 2014 the two courses have been attended by 750 teachers and about 1150 competence units were planned, involving more than 1600 classes (with students from 3 to 18 years old). An important added value of the educational path planning was the opportunity to exchange and compare working experiences. For this reason, LaMMA developed a web platform (http://www.lamma-cres. rete.toscana.it/school/) for creating and consulting the competence units. The platform was also used to upload the final documents describing the conceptual development of the educational paths, the methodological approaches adopted and the products of the students activities (including audio and video). These final documents were also uploaded on the SlideShare's LaMMA web page, with the idea to extend experiences outside of Tuscany. Web analytics for 2016 revealed surprising facts: the 188 documents uploaded received 260 downloads and more than 40000 views, not only from Italy (6650 views), but also from other countries, especially from USA (27 800 views), Canada (about 1000 views) and Russia (900 views).

\subsection{Evaluation survey}

Since 2012 an evaluation questionnaire has been set up by LaMMA staff to assess the outcomes of the educational ac-

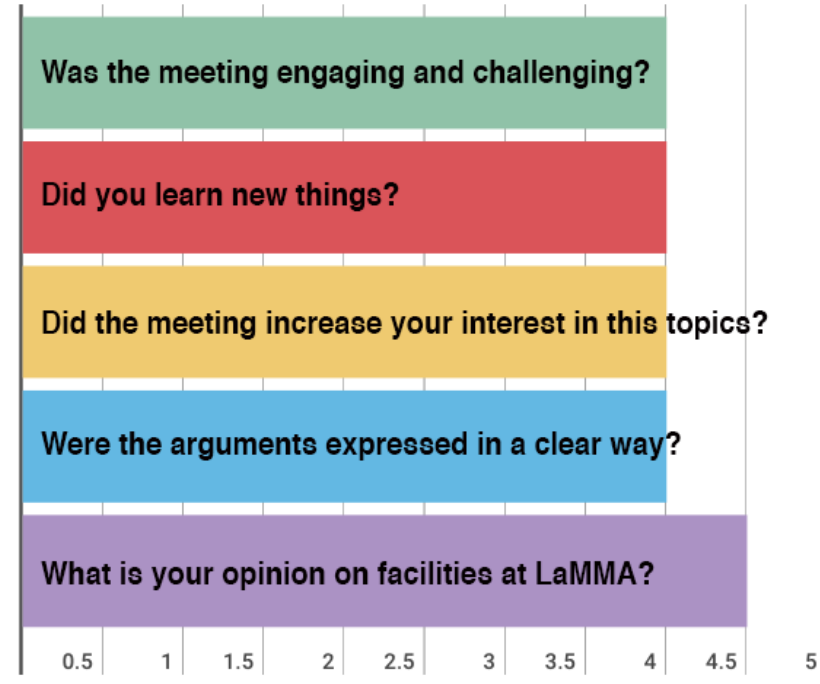

Figure 1. Numbers indicate the median value of the score for the answers to the different questions, on a 5 points Likert scale, from "very poor" (1) up to "very good" (5).

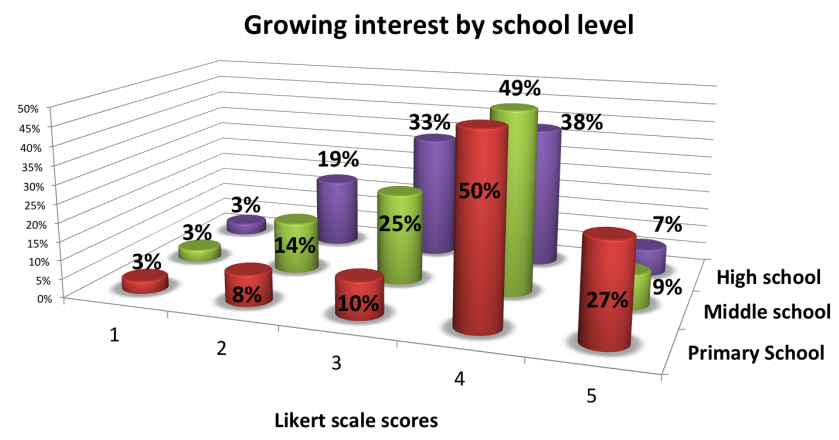

Figure 2. Growing of interest in meteorology as perceived by students of different school levels.

tivities. The evaluation is aimed to measure the level of satisfaction among students visiting the LaMMA labs. It is composed of a short questionnaire which is delivered to students at the end of the visit. Students fill it out once back to school and return it to LaMMA. The survey is anonymous for students who only need to mark school name and class. The questionnaire is structured with six closed-ended questions and three open-ended. For the closed-ended questions, a Likert scale on a response scale 1-to-5 is used to rate each item, where (1) stands for a "very poor" rating, and (5) stands for "very good". The evaluation covers six items: the whole visit experience, the level of engagement, the perceived increase in students knowledge, the increase in interest about meteorology, the clarity of the presentation, and a overall judgment about facilities at LaMMA. The Last three questions are structured as free answers about what they liked the most, what should be improved, and a free comment. 


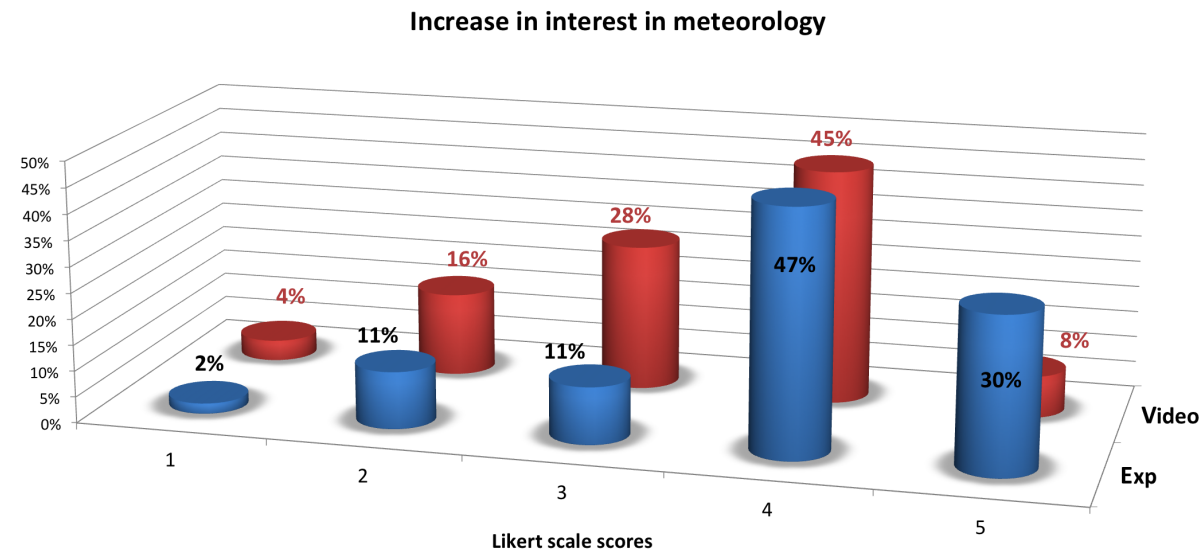

Figure 3. Growing of interest in meteorology as output of the different modules.

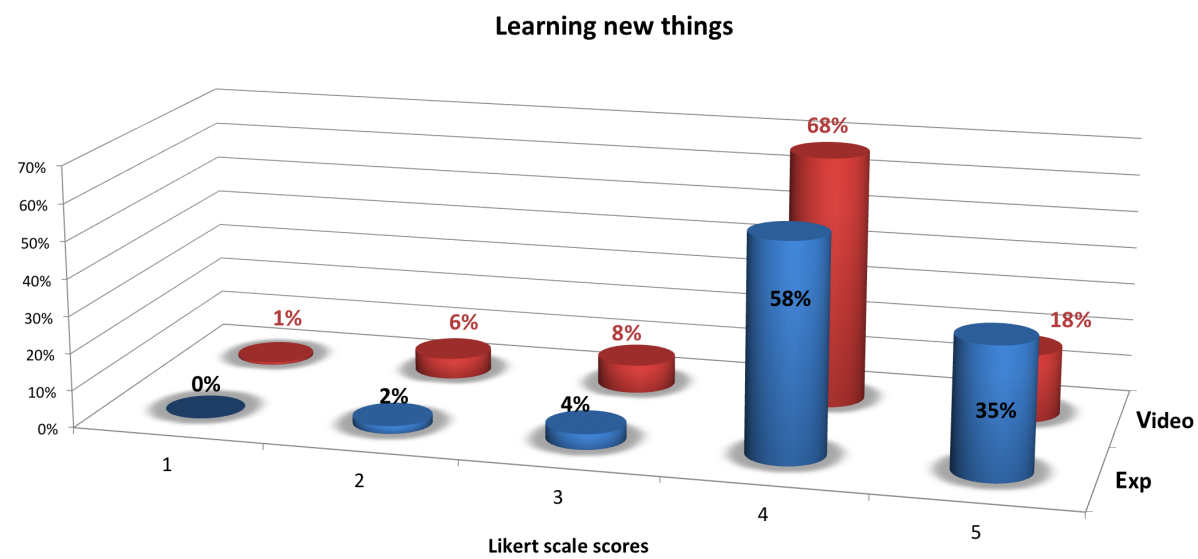

Figure 4. Perceived new knowledge as output of the different modules.

Here we present the data about the evaluation of the education activities ran in 2015-2016, which involved around 50 classes from October 2015 to June 2016. Out of 1000 questionnaires delivered, 351 were returned and were analyzed. The vast majority of survey respondents, 303 , took part in the module "Who wants to be a forecaster" (video hereby), and only 48 in the module "What's up there" (experiments, hereby). Concerning school level, 60 students were form elementary schools, 152 from middle schools and 139 from high Schools. Results of the closed-ended questions are presented.

Generally, the educational modules proposed by LaMMA are very well rated by students, as shown by Fig. 1 . All items reached an average evaluation (calculated as median value) of 4 on a 5 point Likert scale. It corresponds to a "good" judgment about engagement, clarity of exposition, increase in interest about meteorology, and increase in knowledge. LaMMA's facilities obtained a (4.5) evaluation.

Looking more in depth to some items, we may see that the increase in interest in meteorology is more consistent in elementary school students. The column-graph in Fig. 2 shows that $25 \%$ of elementary school students rate as "very good"
(5) the growing interest in meteorology as outcome of the visit, while only 9 and $7 \%$ of middle and high school students express the same evaluation. In contrast, almost $20 \%$ of high school students affirm a "poor" (2) increase in interest in this topic. We also confronted how the different educational modules influenced student evaluation on the increase in interest in meteorology. The column-graph in Fig. 3 shows that students attending experimental module gave a highest rate on Likert scale, with almost $30 \%$ of students choosing "very good" (5) for increase in interest, compared to only $8 \%$ of the video module.

Another point investigated is whether students perceived to have learned new things during the visit. As shown in Fig. 1, the median score gained by this item is 4 out of 5 points. Looking at differences among participants of the two modules, Fig. 4, we see how the highest rating (5) was proposed by $38 \%$ of students taking part in experiments module, compared to $18 \%$ of those attending video module. To better understand these results, we have to remember that participants to experiments module are all young elementary school students with less knowledge on the subject, compared to 
Engaging and challenging modules

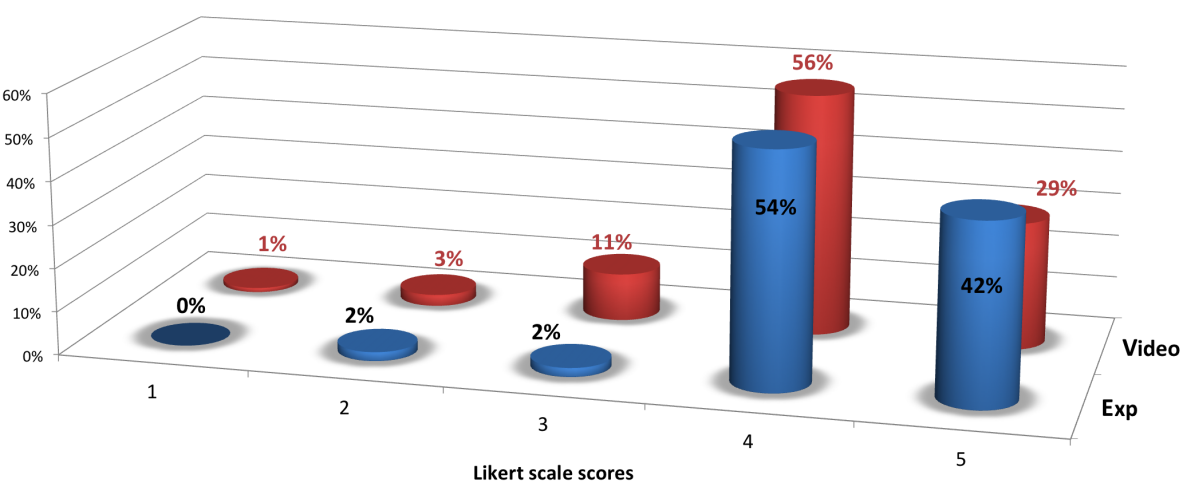

Figure 5. Evaluation of the engagement level of the two modules, as perceived by students.

middle and high school ones. These younger students were more curious and attentive during the visit.

Students considered the visit engaging and challenging. As shown in Fig. 5, no great difference emerges between the two modules. A slightly higher percentage of students taking part at the experiment module choose the highest rating "very good" (5) compared to those attending the video, whose preferences go to "good" (4) rating.

\section{Conclusions}

As part of its outreach activities, LaMMA consortium has been offering since 2011 a set of educational modules in meteorology and climate change. In the last years, hundreds of teachers and students took part in the proposed modules, with many of them visiting LaMMA, meeting researchers and increasing their knowledge about meteorology and intrinsic uncertainty of weather forecasts (Zabini, 2016; Zabini et al., 2015). As the evaluation attests, the LaMMA educational modules are appreciated by students who find them engaging and challenging. This positive judgment is also confirmed in previous years' evaluations (Grasso et al., 2013). From LaMMA's perspective, public outreach and educational activities were, and today still are, a great chance to grow and strengthen LaMMA visibility, spread its scientific mission, and increase trust in its services (Grasso et al., 2014). However, these activities encounter some barriers inside and outside research institutes like LaMMA Consortium: time constraints, due to scientists having other priorities that are perceived as more important; the poor value recognized to outreach activities by the internal evaluation procedures of research institutions and a consequent lack of recognition in tenure process or scientific career; and lastly, outreach activities very often does not have funds to rely on, so they end up to be perceived as a cost more than an earning within research organizations.
Data availability. Data of evaluation survey my be requested by writing at email: comunicazione@lamma.rete.toscana.it.

Competing interests. The authors declare that they have no conflict of interest.

Acknowledgements. Educational activities are realized thanks to many people working at LaMMA. In particular authors want to thank Susanna Lotti, who is in charge of many organizational aspects and helped with data entry. Authors also thank LaMMA Sole Director, dott. Bernardo Gozzini, who always sustained educational and outreach activities.

Edited by: T. Halenka

Reviewed by: two anonymous referees

\section{References}

Andrews, E., Weaver, A., Hanley, D., Shamatha, J., and Melton, G.: Scientists and public outreach: Participation, motivations, and impediments, Journal of Geoscience Education, 53, 281-293, 2005.

Brown, J.: The World Café: Shaping our futures through conversations that matter, http://readhowyouwant.com/, 2002.

Capranico, S.: Role playing: manuale a uso di formatori e insegnanti, Raffaello Cortina, 1997.

Chesler, M. and Fox, R. S.: Role playing Methods in the Classroom, Chicago, Science Research Associates, 1966.

Dusenbery, P., Harold, J., McLain, B., and Curtis, L.: Space Weather Outreach: An informal education perspective, Adv. Space Res., 42, 1837-1843, 2008.

Finarelli, M. G.: GLOBE: A worldwide environmental science and education partnership, Journal of Science Education and Technology, 7, 77-84, 1998.

Flanagan, S.: How does storytelling within higher education contribute to the learning experience of early years students?, The Journal of Practice Teaching and Learning, 13, 162-184, 2015. 
Gibbs, G.: Learning by doing: A guide to teaching and learning methods, London, Further Education Unit, 1988.

Grasso, V., Capecchi, V., Bartolini, G., Benedetti, R., Betti, G., Magno, R., Orlandi, A., Piani, F., Tei, C., Torrigiani, T., and Zabini, F.: "Who want to be a weather forecaster?" Education and Public Outreach at LaMMA Consortium, home of Tuscany weather service, in: Science education and guidance in schools: the way forward, edited by: Raschi, A., Di Fabio, A., and Sebastiani, L., Edizioni ETS, 159-168, 2013.

Grasso, V., Zabini, F., Crisci, A., and Perna, M.: Mappare la partecipazione. L'impronta geografica degli utenti digitali del LaMMA, servizio meteo della Toscana, in: Atti 18a Conferenza Nazionale ASITA, ASITA, 1416, 635-642, 2014.

Laursen, S., Liston, C., Thiry, H., and Graf, J.: What good is a scientist in the classroom? Participant outcomes and program design features for a short-duration science outreach intervention in $\mathrm{K}$ 12 classrooms, CBE-Life Sciences Education, 6, 49-64, 2007.

Mansour, N.: Science-technology-society (STS) a new paradigm in science education, B. Sci. Technol. Soc., 29, 287-297, 2009.

McDrury, J. and Alterio, M.: Learning through storytelling: Using reflection and experience in higher education contexts, Dunmore Press Limited, 2002.

Mintz, A.: Science, society and science centres, História, Ciências, Saúde-Manguinhos, 12, 267-280, 2005.

National Research Council: America's lab report: Investigations in high school science, National Academies Press, 2006

National Research Council: Learning science in informal environments: People, places, and pursuits, National Academies Press, 2009.

Novak, J. D.: Concept mapping: A useful tool for science education, J. Res. Sci. Teach., 27, 937-949, 1990.
Nutter, P. A., Gaarder, D., Gunderson, J., and Drennen, C.: Weather education for disaster recovery: returning control in a time of personal crisis, B. Am. Meteorol. Soc., 91, 1691-1698, 2010.

Osborn, A. F.: Applied Imagination; Principles and Procedures of Creative Problem-solving: Principles and Procedures of Creative Problem-solving, Scribner, 1963.

Owen, H.: Open space technology: A user's guide, Berrett-Koehler Publishers, 2008.

Pandya, R., Smith, D., Ackerman, S. A., Brahma, P. P., Charlevoix, D. J., Foster, S. Q., Gaertner, V. K., Lee, T. F., Hayes, M. J., Mostek, A., Murillo, S. T., Murphy, K. A., Olsen, L., Stanitski, D. M., and Whittaker, T.: A summary of the 18th AMS Symposium on Education, B. Am. Meteorol. Soc., 92, 61-64, 2011.

Pandya, R. E., Foster, S. Q., Smith, D. R., Charlevoix, D. J., Hart, R., Hayes, M. J., McGuirk, M., Murillo, S. T., Murphy, K. A., Stanitski, D. M., and Whittaker, T. M.: A Summary of the 17Th AMS Education Symposium, B. Am. Meteorol. Soc., 90, 15451548, 2009.

Prince, M. J. and Felder, R. M.: Inductive teaching and learning methods: Definitions, comparisons, and research bases, J. Eng. Educ., 95, 123-138, 2006.

Shouse, A. W., Schweingruber, H. A., and Duschl, R. A. (Eds.): Taking science to school: Learning and teaching science in grades K-8, National Academies Press, 2007.

Zabini, F.: Mobile weather apps or the illusion of certainty, Meteorol. Appl., 23, 663-670, 2016.

Zabini, F., Grasso, V., Magno, R., Meneguzzo, F., and Gozzini, B.: Communication and interpretation of regional weather forecasts: a survey of the Italian public, Meteorol. Appl., 22, 495-504, 2015. 